\title{
Preparation and characterization of a novel optical chemical sensor for determination of trace amounts of Praseodymium ion by UV/Vis spectrophotometry
}

\author{
Kheibar Dashtian, Rouholah Zare-Dorabei ${ }^{*}$ \\ Research Laboratory of Spectrometry \& Micro and Nano Extraction, Department of \\ Chemistry, Iran University of Science and Technology, Tehran, Iran \\ *Corresponding author: E-mail address: zaredorabei@iust.ac.ir (Rouholah Zare- \\ Dorabei) \\ Tel: +982177240646 \\ Fax: +982177491204
}




\begin{abstract}
In the present work, a novel optical chemical sensor (optode) was prepared based on impregnation of $\mathrm{N}, \mathrm{N}^{\prime}$-bis (salicylidene)-1, 3-ethylenediamine (BESA) Schiff base into mesoprous SBA-15 paste for determination of trace amounts of Praseodymium (Pr) ion by UV/Vis spectrophotometry. The sensor was fabricated by dip-coating triacetylcellulose membrane into indicator solution. The proposed optical sensor was prepared through a routine procedure and characterized by various techniques such as ATR-FT-IR and SEM analyses. This optode exhibited a linear range of 10 to $190 \mathrm{ng} \mathrm{mL}^{-1}$ for $\operatorname{Pr}(\mathrm{III})$ ion concentration with a detection limit of $5.0 \mathrm{ng} \mathrm{mL}^{-1}$. The value of the response time for the newly synthesized optode was within $100 \mathrm{~s}$ while depending on the $\operatorname{Pr}(\mathrm{III})$ ion concentration. The proposed optode showed low detection limit, fast response time and high selectivity with respect to the group of transition metal ions $\left(\mathrm{Ce}^{3+}, \mathrm{Nb}^{3+}, \mathrm{La}^{3+}, \mathrm{Cr}^{3+}, \mathrm{Zn}^{2+}, \mathrm{Hg}^{2+}\right.$, and $\mathrm{Fe}^{2+}$ ions). The optode was successfully regenerated with a mixture of thiourea and $\mathrm{NaOH}$ solution and the response was reversible with the relative standard deviation (R.S.D.) of $1.6 \%$. The optode was stable and stored for at least 17 days without any considerable change in its sensitivity. Finally, the developed optode was applied to determine the $\operatorname{Pr}(\mathrm{III})$ ions in spiked samples.
\end{abstract}

Keywords: Optical sensor; UV/Vis spectrophotometry; Praseodymium; Mesoprous SBA-15 past; Dip-coating; Triacetyl cellulose 


\section{Introduction}

Lanthanides are important elements from an industrial point of view. Praseodymium which is one of the most abundant rare earths, has attracted an extensive interest due to its application in atomic batteries [1], color televisions, fluorescent lamps, energy-saving lamps and glasses as well as a core material for carbon arc lights which are generally used in the motion picture industry. It is dumped through different places in the environment, and mainly can be produced at petroleum industries [2]. It can also penetrate into the environment by household stuffs which are thrown away. Praseodymium is being gradually accumulated by soils and water resources, and eventually would lead to increase the concentrations of $\operatorname{Pr}(\mathrm{III})$ in human body, animals and soil particles via the food chain [3]. Water soluble compounds of praseodymium are considered mildly toxic, while its insoluble compounds are non-toxic. According to the some experiments had been performed on animals, praseodymium and its compounds caused lung and liver damage $[4,5]$. In rats, inhalation of praseodymium caused pulmonary edema and dyspnea and caused liver edema, pleural effusions, and pulmonary hyperemia. Exposure to praseodymium compounds in humans may cause lung disease [6]. Therefore, the monitoring of low and high level of $\operatorname{Pr}(\mathrm{III})$ ions in accurate, repeatable and reversible way is of high importance. Nowadays, many instrumental methods have been reported in order to determination of $\operatorname{Pr}(\mathrm{III})$ ion in real sample including absorption spectra of 4d electron transitions [7], derivative spectroscopy [8], flotation-spectrophotometric [9], polyvinylchloride (PVC)-membrane electrode [3], PVC-membrane sensor [10-11], resonance light scattering [12], fluorescence enhancement sensor [2], chemiluminescence [13] and some other spectroscopic methods [6, 14]. However, all of these techniques usually require proficiency and infrastructure backup. Moreover, their performance is expensive and nearly time consuming. Therefore, a simple and low cost method is needed to be developed for the analysis of $\operatorname{Pr}(\mathrm{III})$ ions while dealing with large number of environmental samples. In this cases, optical sensors can be used for this purposes with simple instrumentation and suitable for array fabrication. Among different factors affecting the outcome of optical sensors, type of polymer matrix has a significant effect $[15,16]$. Many supporting materials such as PVC [17-19] or sol-gel $[20,21]$ can be employed to prepare the optical sensors. In this work, a mesoprous SBA-15 matrix was synthesized by hydrothermal method introduced by Tadjarodi et al. [22]. The mesoprous SBA-15 past was formed by the method proposed by Michael Gratzel and coworkers for $\mathrm{TiO}_{2}$ nanoparticles powder where the difference is that the $\mathrm{TiO}_{2}$ was used instead of mesoprous SBA-15 [23]. The current study presents a highly selective 
Praseodymium sensor based on a novel technique and ionophore which is corresponds to determination of $\operatorname{Pr}($ III) ions with a wide concentration range and low detection limit.

\section{Experimental}

\subsection{Reagents and Materials}

Buffer solutions were prepared from boric acid/sodium acetate and phosphoric acid (0.04 mol L ${ }^{-1}$ each), and then $\mathrm{pH}$ adjustments were carried out by the addition of sodium hydroxide and hydrochloric acid solutions $\left(1.0 \mathrm{~mol} \mathrm{~L}^{-1}\right)$. A stock solution of $1000 \mathrm{ppm}$ $\operatorname{Pr}(\mathrm{III})$ solution was prepared by weighing $0.025 \mathrm{~g}$ of praseodymium nitrate hexahydrate (Fluka) and adjusting the volume to $25 \mathrm{~mL}$. The standard solutions of lower concentrations were prepared by suitable dilutions of the stock solution with deionized water. Metal cations applied for evaluation of the effect of interferences were based on their nitrate salts.

\subsection{Instrumentation}

Spectroscopic measurements were performed using a PG Instruments T80+ UV/Vis spectrophotometer with $1.0 \mathrm{~cm}$ quartz cells. Also, the $\mathrm{pH}$ measurements were carried out with a Methrom double junction glass electrode and a Methrom $691 \mathrm{pH}$ meter. The morphology of samples was studied by scanning electron microscopy (SEM: KYKY-EM3200) under an acceleration voltage of $26 \mathrm{KV}$. The FT-IR spectra of compounds were recorded on a shimadzu instrument in the range of $500-4500 \mathrm{~cm}^{-1}$. X-ray diffraction (XRD) pattern was recorded by an automated Philips X'Pert X-ray diffractometer (40 kV and $30 \mathrm{~mA})$ for $2 \theta$ values over $2-10^{\circ}$. The BET Surface area and BJH analysis were studied by Micromeritics Instrument. The ultrasonic homogenization was performed using an elmasonic S 60/ $(\mathrm{H})$ sonicator.

\subsection{Preparation of mesoporous $S B A-15$ paste}

SBA-15 was synthesized by the hydrothermal method introduced by Zhao et al., using Pluronic P123 as a template, tetraethylortosilicat (TEOS) and $\mathrm{HCl}$ to cause the media acidic $[22,24]$. To do this, $4.0 \mathrm{~g}$ Pluronic of P123 ( $\mathrm{Mw}=5800), 90 \mathrm{~mL}$ of $2.0 \mathrm{M}$ hydrochloric acid and $21 \mathrm{~mL}$ deionized water was stirred for 5.0 hours at room temperature. Then, $6.8 \mathrm{~mL}$ of TEOS was slowly added to the above solution and stirred at the $40{ }^{\circ} \mathrm{C}$ for 24 hours. The mixture was kept in an oven at $100{ }^{\circ} \mathrm{C}$ for 24 hours in order to get sterilized. The synthesized 
product was then filtered, washed, dried, and calcinated at $600{ }^{\circ} \mathrm{C}$ for $6.0 \mathrm{~h}$ in order to remove the residual templates.

Mesoprous SBA-15 paste was prepared using the method proposed by Michael Gratzel et al. The fabrication process for SBA-15 pastes in the ambient air at room was described in Fig. 1. At each step, liquids were added drop wise into an agate mortar. The diameter of the mortar was ca. $5.0 \mathrm{~cm}$. The SBA-15 powders stuck inside of the mortar should be removed by a plastic spatula in order to grind large aggregates. The dispersed particles of SBA-15 were transferred into a tall beaker by using excess amounts of ethanol $(100 \mathrm{ml})$ and stirred with a $2.0 \mathrm{~cm}$ long magnet tip at $300 \mathrm{rpm}$. Anhydrous terpineol (Fluka) and the mixture solution of two ethyl celluloses in ethanol were added, followed by stirring and sonication. The contents in dispersion were concentrated by evaporator at $40{ }^{\circ} \mathrm{C}$ into the oven.

\section{Fig. 1}

\subsection{Ligand Preparation}

$\mathrm{N}, \mathrm{N}^{\prime}$-bis(salicylidene)-1,3-ethylenediamine (BSEA) is a tetradentate ligand without any amino group in the ring. The dye molecules can be linked to the cellulose acetate film by special treatment. BSEA was synthesized by refluxing a mixture of $3.28 \mathrm{~g} \mathrm{~N}$-(2-aminoethyl)salicylaldimine (AESI, taken from our previous report (Ref. [25])), 2, 4-dihydroxy benzaldehyde $(2.76 \mathrm{~g})$ and ethanol $(50 \mathrm{~mL})$ in an oil bath at $75^{\circ} \mathrm{C}$ for $3 \mathrm{~h}$. Then, the reaction mixture was cooled to room temperature. The yellow crystals were filtered, and subsequently were washed with ethanol and dried at room temperature (Fig. 2) [25].

\section{Fig. 2}

\subsection{Preparation of the sensing film}

The immobilized indicator on triacetyl cellulose was prepared according to the following procedure: The transparent triacetyl cellulose membranes were produced from waste photographic film tapes that have been previously treated for a few minutes with commercial hypochlorite in order to remove the colored gelatinous layers. In order to increase the porosity of the membrane, the triacetyl cellulose film was hydrolyzed to deesterify the acetyl groups. This was accomplished by treating the membrane with $1.0 \mathrm{~mol} \mathrm{~L}^{-1}$ $\mathrm{NaOH}$ solution for $48 \mathrm{~h}$. The film was then washed with distilled water before being used [26].

To prepare the coating solution, $0.1 \mathrm{~g}$ SBA-15 paste was dispersed in $6.0 \mathrm{~mL}$ ethylenediamine for $1.0 \mathrm{~h}$. then, $0.1 \mathrm{~mL}$ (3-chloropropyl) triethoxysilane (CPTES) was added 
to the resulting solution, and the reaction was continued for $1.0 \mathrm{~h} .10 \mathrm{mg}$ BSEA was then added to the solution and the mixture was dispersed again for $2.0 \mathrm{~h}$. The prepared solution was kept for $48 \mathrm{~h}$ at ambient temperature and then was dispersed for $1.0 \mathrm{~h}$. The film was immersed into the indicator solution for $2.0 \mathrm{~min}$ at ambient temperature. Then, they were washed with water for removing excess ethylenediamine and the loosely trapped indicator. Prepared membranes were kept under $1.0 \mathrm{M} \mathrm{NaOH}$ solution when they were not being used (Fig. 2).

\section{Results and discussions}

\subsection{Sample properties}

The characterization of mesoporous SBA-15 was carried out by XRD, SEM, FT-IR, BET and BJH analysis. The FT-IR spectrum of SBA-15 (Fig. 3a) exhibits a large broad band at $3435 \mathrm{~cm}^{-1}$ and $1630 \mathrm{~cm}^{-1}$, which belongs to the $\mathrm{O}-\mathrm{H}$ bond stretching and bending of the surface silanol groups, respectively [27]. The vibrations of $\mathrm{O}-\mathrm{Si}-\mathrm{O}$ and $\mathrm{Si}-\mathrm{O}$ of silanol groups were appeared at 1083 and $960 \mathrm{~cm}^{-1}$, respectively [22]. The low-angle XRD patterns of SBA15 has been exhibited two peaks $(110,200)$ and a single strong peak (100), which can be confirmed on hexagonal and order lattice (Fig. 3b) [28]. The transition electron microscopy (TEM) image of the SBA-15 was used for studying the specification morphology. TEM image indicates a rod and regular hexagonal structure for SBA-15 (Fig. 3c) [29]. Textural and physicochemical properties of SBA-15 such as the pore diameter $\left(\mathrm{D}_{\mathrm{BJH}}\right)$, the BET surface area and total pore volume $\left(\mathrm{V}_{\text {total }}\right)$ are given in Table 1. Fig. 3d displays a typical type IV nitrogen sorption isotherm in accordance with the defined behavior of SBA-15 [30-36].

Fig. 3 \& Table 1.

The characterization of hydrolyzed cellulose acetate and sensing film was carried out by SEM and ATR-FT-IR while immobilized BSEA on hydrolyzed cellulose acetate by proposed method for designing of novel optical sensor was derived. The ATR-FT-IR spectrum of hydrolyzed cellulose acetate (Fig. 4a) exhibits a small band at $3435 \mathrm{~cm}^{-1}$, which belongs to the $\mathrm{O}-\mathrm{H}$ bond stretching of the surface cellulose acetate groups [37], After the modification of triacetylcellulose with SBA-15-BSEA, the ATR-FT-IR spectrum (Fig. 4a) exhibits a large broad band at $3435 \mathrm{~cm}^{-1}$, which belongs to the $\mathrm{O}-\mathrm{H}$ bond stretching of the 
surface silanol groups [22]. The vibrations of $\mathrm{O}-\mathrm{Si}-\mathrm{O}$ and $\mathrm{Si}-\mathrm{O}$ of silanol groups were appeared at 1083 and $960 \mathrm{~cm}^{-1}$, respectively, and also a new peak at $2931 \mathrm{~cm}^{-1}$ was displayed, which belongs to the stretching and bending vibrations of $\mathrm{C}-\mathrm{H}$ bond in propyl group. The new peak appeared at $1639 \mathrm{~cm}^{-1}$ is related to $\mathrm{C}=\mathrm{N}$ from BSEA, verifying the successful immobilization of $\mathrm{N}, \mathrm{N}^{\prime}$-bis (salicylidene)-1,3-ethylenediamine [22]. Fig. 4b and c show SEM images of triacetylcellulose and mesoporous SBA-15-BSEA coating, respectively. It can be observed that SBA-15-BSEA was coated by triacetyl cellulose. The uncoated triacetyl cellulose was relatively smooth (Fig. 4b). However, the triacetyl cellulose fully covered by the SBA-15-BSEA coating revealed homogeneous dispersion over the large area (Fig. 4c).

\section{Fig. 4}

\subsection{Spectral characteristics of BSEA immobilized on hydrolyzed cellulose acetate}

After immobilization of BSEA on hydrolyzed cellulose acetate by proposed method and current method, the absorbance spectra of the two optodes were recorded against blank thin film (Fig. 5a). As seen, in comparison with the current method, the optical sensor prepared by the proposed process indicated a higher increase in adsorption intensity which is due to the high surface area and $\mathrm{OH}$ bonded of indicator with support. The absorbance spectra of the optode before and after reaction with different concentrations of $\operatorname{Pr}(\mathrm{III})$ ions at pH 5.0 (Fig. $5 b)$ reveal that complex formation caused a change in absorbance spectra $420 \mathrm{~nm}$. This observation could be attributed to the fact that the structured conformation of the immobilization indicators is more planar than that of its soluble analogue. A strong absorption maxima at $420 \mathrm{~nm}$ was also observed which was the favorite wavelength for further analytical measurements.

Fig. 5

\section{3. pH effect}

The influence of $\mathrm{pH}$ on the changes in absorbance of the optode was studied over a $\mathrm{pH}$ range between 2.0 and 5.0 by changing the $\mathrm{pH}$ of the solution for $90 \mathrm{ng} \mathrm{mL}^{-1} \mathrm{Pr}(\mathrm{III})$ solutions at $420 \mathrm{~nm}$. It can be concluded, over the $\mathrm{pH}$ 6.0, formation of hydroxyl complex of $\operatorname{Pr}(\mathrm{III})$ ions occurred. Therefore, the effect of $\mathrm{pH}$ on the optode was studied in the $\mathrm{pH}$ range of 2.05.0 by changing the universal buffer $\mathrm{pH}$ (Fig. 6). As seen, the maximum response of optode 
was obtained at $\mathrm{pH}$ 5.0, because BSEA is not protonated and hydroxyl complex of $\operatorname{Pr}(\mathrm{III})$ ions are not formed, while formation of the complex between $\mathrm{OH}$ group and imines group on BSEA was easily observed. At $\mathrm{pH}<5.0$ the response of the sensor membrane changed which is due to the proton binding by imines nitrogen or other ionophore functional group protonation. $\mathrm{pH}$ of 5.0 was selected for subsequent works in order to achieve high efficiency and good selectivity.

\section{Fig. 6}

\subsection{Response time}

Response time was defined as the time between the instant at which the optical sensor are dipped in the sample solution, and the first instant at which the absorbance of the optode becomes equal to its steady-state value (i.e. being reached to $90 \%$ of the final value). In this study, the practical response time was tested by recording the absorbance change from a pure buffer ( $\mathrm{pH}=5.0$ ) to a buffered $\mathrm{Pr}(\mathrm{III})$ solution of $90 \mathrm{ng} \mathrm{mL}^{-1}$ and results is shown in Fig. 7 . As seen, the response time of the proposed optical sensor was $100 \mathrm{~s}$. This is likely due to the fast exchange kinetics of complexation of $\operatorname{Pr}$ (III) ion with BSEA at the test solution-optode interface.

\section{Fig. 7}

\subsection{Analytical figure of merit}

All optimized parameters mentioned above are employed in order to develop a $\operatorname{Pr}(\mathrm{III})$ ion calibration curve. The calibration graphs for $\operatorname{Pr}(\mathrm{III})$ ion was derived by plotting absorbance change values as a function of the Pr(III) ions concentration during a time of 100 $\mathrm{s}$ after the contact between solution and sensing phase was being linear in the range $10-190$ $\mathrm{ng} \mathrm{mL}^{-1}$. The following equation with the correlation coefficient $\left(\mathrm{R}^{2}\right)$ of 0.9923 was obtained:

$$
\Delta \mathrm{Abs}=0.0012[\mathrm{Pr}(\mathrm{III})]+0.0456
$$

where $\operatorname{Pr}(\mathrm{III})$ is concentration of $\operatorname{Pr}(\mathrm{III})$ in $\mathrm{ng} \mathrm{mL}^{-1}$ and $\Delta \mathrm{Abs}$ is a absorbance difference (defined as the difference between the absorbance of the immobilized BSEA solely and the absorbance of Pr(III)-BSEA complex at $420 \mathrm{~nm}$ (Fig. 8). In this case, the limit of detection can be defined as the sample concentration that yielding was $5.0 \mathrm{ng} \mathrm{ml}^{-1}$.

\section{Fig. 8}




\subsection{Repeatability and reproducibility}

The repeatability and reproducibility are two important properties of the chemical sensors for identification their applicability. The repeatability was studied using a single membrane by preparing five standard solution of $\operatorname{Pr}(\mathrm{III})$ ion in $90 \mathrm{ng} \mathrm{mL} \mathrm{m}^{-1}$ independently in similar conditions, followed by, measuring the absorbance of all sensors under optimum conditions at $420 \mathrm{~nm}$. The coefficient of variation of sensor response found to be $1.6 \%$. In addition, reproducibility was tested by obtaining five optodes independently through similar conditions, and afterwards, measuring the absorbance of all optodes under optimum conditions for $90 \mathrm{ng} \mathrm{mL} \mathrm{m}^{-1} \operatorname{Pr}(\mathrm{III})$ ion solution at $420 \mathrm{~nm}$. The relative standard deviation (R.S.D.) for these determinations was $2.1 \%$.

\subsection{Effect of the foreign ions}

One of the most important characteristics of an optical membrane sensor is its relative response towards the primary ion over other ions present in the solution. To determine the selectivity of the optode film, the film was examined in the presence of other metal ions in order to detect $\operatorname{Pr}(\mathrm{III})$ ions at the concentration of $90 \mathrm{ng} \mathrm{mL}^{-1}$. Tolerance limit was taken as the concentration causing an error of $\pm 5.0 \%$ in the $\operatorname{Pr}($ III) assay. The results are summarized in Table 2. The high selectivity of the optode film for $\operatorname{Pr}(\mathrm{III})$ ions over other taken cations and anions most probably arises from the strong tendency of the complexation (BSEA) toward $\operatorname{Pr}(\mathrm{III})$ ions.

\section{Table 2.}

\subsection{Life time stability of optode}

The Life time stability of optode was determined by adding a buffer solution $(\mathrm{pH}=5.0)$ into the cuvette containing the film. The change in the absorbance after keeping the optode in buffer solution $(\mathrm{pH}=5.0)$ for 3.0 weeks was measured at $420 \mathrm{~nm}$. The absorbance values of optode were decreased only about $2.9 \%$ over a period of 3.0 weeks. This result indicates that the sensor is surprisingly stable; therefore, the prepared membranes were kept under water, while not being used in order to prevent them from drying out. Additionally, stability of film response was investigated over 6.0 weeks under ambient conditions, which confirmed that the film was stable over this period of time. 


\subsection{Optode regeneration}

For an optode membrane to perform suitably, absorbance change must be reversible. A good sensor should completely be regenerable at short time. Some tests were conducted with several number of reagents to reverse the absorbance of $\operatorname{Pr}(\mathrm{III})$ ions complex. Complexing agents such as EDTA, thiourea and sulfosalcylic acid have a partial reverse effect, and prolonged exposure to them showed no further improvement in reversibility of the optode [38, 39]. According to our results, the sensor can be regenerated and reused by exposure to the solution of thiourea $(1.0 \mathrm{M})$ and $\mathrm{NaOH}(0.1 \mathrm{M})$. Furthermore, the solution of thiourea $(1.0 \mathrm{M})$ and $\mathrm{NaOH}(0.1 \mathrm{M})$ revealed a short regeneration time (Fig. 9, about $60 \mathrm{~s}$ ). After the second regeneration, a drift of about $1.7 \%$ was obtained in response of the sensor film.

\section{Fig. 9}

\subsection{Praseodymium determinations in aqueous media and recovery tests}

The proposed optical sensor was applied to determine the $\operatorname{Pr}(\mathrm{III})$ ion content in water samples through spiking method. The amounts of the $\operatorname{Pr}(\mathrm{III})$ ions added to the water samples could be efficiently determined by the sensor. In order to investigate the accuracy of the method, a comparison was carried out between the results obtained by the proposed method and those achieved by ICP-OES. This technique cannot be successfully applied for the determination of $\operatorname{Pr}(\mathrm{III})$ ions in this concentration range.

The recovery tests were performed using real samples by using spike method. The test for each sample was carried out in triplicate measurements. As it is obvious from Table 3, $\operatorname{Pr}(\mathrm{III})$ can be accurately recovered from the solutions with a remarkable recovery percentage between $97.88 \%$ and $104.77 \%$.

\section{Table 3.}

\section{Conclusion}

In this work, a new procedure was introduced to fabricate a sensitive and selective optical sensor for $\operatorname{Pr}(\mathrm{III})$ ions determination based on covalent bound of $\mathrm{N}, \mathrm{N}^{\prime}$ bis(salicylidene)-1,3-ethylenediamine (BSEA) with hydrolyzed cellulose acetate. The sensor was easily prepared, readily regenerated with a thiourea and $\mathrm{NaOH}$ solution and demonstrated a long lifetime. The developed sensor can be used for the determination of

$\operatorname{Pr}(\mathrm{III})$ ions in the range of $10-190 \mathrm{ng} \mathrm{mL}^{-1}$ with a good limit of detection (LOD $=5.0 \mathrm{ng}$ 
$\left.\mathrm{mL}^{-1}\right)$ and short response time $(\sim 100 \mathrm{~s})$. The fabricated optode elucidates high performance in terms of some important parameters such as reproducibility, reversibility, stability, response time and leaching characteristics. Moreover, this optode offers low limit of detection, fast response time and long-term stability in comparison with some sensors which are used for other supporting materials. The characteristics of the proposed $\operatorname{Pr}($ III) optical sensor were also compared with other analytical methods for determination of $\operatorname{Pr}(\mathrm{III})$ reported in the literature (Table 4). The linear range, detection limit and relative standard deviation of the proposed optode is acceptable. However, to the best of our knowledge, no attempt has been made to report an optical sensor membrane with chip reagents applicable for Pr (III) ions determination in solution.

\section{Table 4.}

\section{Acknowledgements}

The financial support of this study by Iran University of Science and Technology and Nano Technology Initiative Concil are gratefully acknowledged. The author acknowledges financial support from the Iran National Science Foundation (INSF). 
[1] S.H. Yin, W.Y. Wu, F.Y. Zhang, Q. Zheng, X. Bian, Selective Separation of Praseodymium (III) by Di-(2Ethylhexyl) Phosphoric Acid Using the Complexing Agent, Adv. Mater. Res., 610 (2013) 452-456.

[2] M. Ganjali, M. Hosseini, A. Ghafarloo, M. Khoobi, F. Faridbod, A. Shafiee, et al., Selective recognition of $\mathrm{Pr}^{3+}$ based on fluorescence enhancement sensor, Mater. Sci. Eng., C, 33 (2013) 4140-4143.

[3] H.A. Zamani, M.R. Ganjali, P. Norouzi, S. Meghdadi, Application of Novel Praseodymium (III) PVC-Membrane Electrode for Determination of Pr (III) Ions in Soil and Sediment Samples, Anal. Lett., 41 (2008) 902-916.

[4] A. Dubinin, A. Rozanov, Geochemistry of rare earth elements and thorium in sediments and ferromanganese nodules of the Atlantic Ocean, Lithol. Miner. Resour. 36 (2001) 268-279.

[5] R.C. Oliveira, C. Jouannin, E. Guibal, O. Garcia, Samarium (III) and praseodymium (III) biosorption on Sargassum sp.: batch study, Process Biochem. 46 (2011) 736-744.

[6] J. Wang ,P.A. Farias, J.S. Mahmoud, Trace determination of lanthanum, cerium, and praseodymium based on adsorptive stripping voltammetry, Anal. Chim. Acta, 171 (1985) 215-223.

[7] V.K. Gupta, R.N. Goyal, M.K. Pal, R.A. Sharma, Comparative studies of praseodymium (III) selective sensors based on newly synthesized Schiff's bases, Anal. Chim. Acta, 653 (2009) 161-166.

[8] N. Wang, X. Ren, Z. Si, W. Jiang, C. Liu, X. Liu, Derivative spectrophotometric determination of praseodymium in rare earth mixtures with lomefloxacin, Talanta, 51 (2000) 595-598.

[9] V. Bhagavathy, T. Prasada Rao, A. Damodaran, Flotation-spectrophotometric determination of praseodymium with 5, 7-dichloroquinolin-8-ol and Rhodamine 6G, Anal. Chim. Acta 280 (1993) 169-172.

[10] H.A. Zamani ,M. Masrournia, S. Sahebnasagh, M.R. Ganjali, Fabrication of a Praseodymium (III) PVCMembrane Sensor Based on N' 1, N' 2-Bis (2-oxo-1, 2-diphenylethylidene) ethanedihydrazide, Anal. Lett. 42 (2009) 555-70.

[11] H.A. Zamani, A. Arvinfar, F. Rahimi, A. Imani, M.R. Ganjali, S. Meghdadi, Praseodymium analysis in aqueous solution by $\mathrm{Pr}^{3+}$-PVC membrane sensor based on N-bis (4-hydroxysalicylidene)-1-3phenylenediamine, Mate. Sci. Eng.: C, 31 (2011) 307-312.

[12] S. Sun, X. Wu, J. Yang, L. Li, Y. Wang, Determination of dysprosium by resonance light scattering technique in the presence of BPMPHD, Spectrochim. Acta A 60 (2004) 261-264.

[13] M. Hosseini, M.R. Ganjali, Z. Vaezi, F. Faridbod, B. Arabsorkhi, M.H. Sheikhha, Selective recognition of dysprosium(III) ions by enhanced chemiluminescence CdSe quantum dots, Spectrochim. Acta A 121 (2014) 116-120.

[14] T. Utikal, E. Eichhammer, L. Petersen, A. Renn, S. Götzinger, V. Sandoghdar, Spectroscopic detection and state preparation of a single praseodymium ion in a crystal, Nat. Commun., 5 (2014) 3627.

[15] S. Lépinay, A. Ianoul, J. Albert, Molecular imprinted polymer-coated optical fiber sensor for the identification of low molecular weight molecules, Talanta, 128 (2014) 401-407.

[16] A. Kisiel, K. Kłucińska, Z. Głębicka, M. Gniadek, K. Maksymiuk, A. Michalska, Alternating polymer micelle nanospheres for optical sensing, Analyst, 139 (2014) 2515-2524.

[17] M. Benounis, Novel phosphate-selective poly(vinyl chloride-co-vinyl acetate-co-vinyl alcohol) membrane optode with carrier based on tin compound, Sens. Actuatrs B: Chem. 216 (2015) 57-63.

[18] A.R. Firooz, A.A. Ensafi, K.S. Hoseini, N. Kazemifard, Development of a highly sensitive and selective mercury optical sensor based on immobilization of bis (thiophenal)-4, 4'-methylenedianiline on a PVC membrane, Mate. Sci. Eng.: C, 38 (2014) 73-78.

[19] M. Rezayi, M. Gholami, N.R. Said, Y. Alias, A novel polymeric membrane sensor for determining titanium (III) in real samples: Experimental, molecular and regression modeling, Sens. Actuatrs B: Chem. 224 (2016) 805-813.

[20] A. Samadi-Maybodi, V. Rezaei, A new sol-gel optical sensor with nonporous structure for determination of trace zinc, Sens. Actuators B: Chem., 199 (2014) 418-423.

[21] M. Attia, H. Zoulghena, M. Abdel-Mottaleb, A new nano-optical sensor thin film cadmium sulfide doped in sol-gel matrix for assessment of $\alpha$-amylase activity in human saliva, Analyst, 139 (2014) 793-800.

[22] A. Tadjarodi, V. Jalalat, R. Zare-Dorabei, Adsorption of La (III) in aqueous systems by N-(2-hydroxyethyl) salicylaldimine-functionalized mesoporous silica, Mater. Res. Bull., 61 (2015) 113-119. 
[23] S. Ito, P. Chen, P. Comte, M.K. Nazeeruddin, P. Liska, P. Péchy, et al., Fabrication of screen-printing pastes from $\mathrm{TiO}_{2}$ powders for dye-sensitised solar cells, Progress in Photovoltaics: Res. Appl., 15 (2007) 603-612.

[24] M. Jamshidi, M. Ghaedi, K. Dashtian, S. Hajati, New ion-imprinted polymer-functionalized mesoporous SBA-15 for selective separation and preconcentration of $\mathrm{Cr}$ (III) ions: modeling and optimization, RSC Adv. 5 (2015) 105789-105799.

[25] R. Zare-Dorabei, K. Dashtian, V. Jalalat ,Lanthanum (III) Ion Determination by a New Design Optical Sensor, IEEE Sens. J. 15 (2015) 6715-6721.

[26] R. Zare-Dorabei, M.R. Ganjali, H. Rahimi, H. Farahani, P. Norouzi, Design and fabrication of a novel optical sensor for determination of trace amounts of lutetium ion, Curr. Chem. Lett., 2 (2013) 125-134.

[27] J. Liu, Y. Liu, W. Yang, H. Guo, H. Zhang, Z. Tang, et al., A novel and simple strategy for the direct synthesis bimetallic mesoporous materials Zr-La-SBA-15, Mater. Lett., 128 (2014) 15-18.

[28] M. Boutros, M.E. Gálvez, T. Onfroy, P. Da Costa, Influence of synthesis parameters of SBA-15 supported palladium catalysts for methane combustion and simultaneous NO reduction, Micropor. Mesopor. Mat. 183 (2014) 1-8.

[29] D. Carmona, F. Balas, J. Santamaria, Pore ordering and surface properties of FDU-12 and SBA-15 mesoporous materials and their relation to drug loading and release in aqueous environments, Mater. Res. Bull., 59 (2014) 311-322.

[30] L. Chen, Z. Zheng, J. Wang, X. Wang, Mesoporous SBA-15 end-capped by PEG via l-cystine based linker for redox responsive controlled release, Micropor. Mesopor. Mat. 185 (2014) 7-15.

[31] A. Tadjarodi; V. Jalalat, R. Zare-Dorabei, Synthesis and characterization of functionalized SBA-15 mesoporous silica by N, N'-bis(salicylidene)-1,3-ethylenediamine Schiff base, J. NanoStruct. 4 (2013) 477-482.

[32] R. Zare-Dorabei, V. Jalalat, A. Tadjarodi, Central composite design optimization of Ce(III) ion removal from aqueous solution using modified SBA-15 mesoporous silica, New J. Chem. 40 (2016) 5128-5134.

[33] M.R. Awual, M.M. Hasan, A. Shahat, Functionalized novel mesoporous adsorbent for selective lead(II) ions monitoring and removal from wastewater, Sens. Actuators B: Chem., 203 (2014) 854-863.

[34] M.R. Awual, M.A. Khaleque, M. Ferdows, A.M.S. Chowdhury, T. Yaita, Rapid recognition and recovery of gold(III) with functional ligand immobilized novel mesoporous adsorbent, Microchem. J. 110 (2013) 591-598.

[35] S.A. El-Safty, M.A. Shenashen, M. Ismael, M. Khairy, M.R. Awual, Optical mesosensors for monitoring and removal of ultra-trace concentration of $\mathrm{Zn}$ (II) and $\mathrm{Cu}$ (II) ions from water, Analyst 137 (2012) 52785290.

[36] R. Zare-Dorabei, M. Shamsedini Darbandsari, A. Moghimi, M. Saghanejhad Tehrani, S. Nazerdeylami, Synthesis, characterization and application of Cyclam-modified magnetic SBA-15 as a novel sorbent and its optimization by central composite design for adsorption and determination of trace amount of lead ions, RSC Adv., DOI: 10.1039/C6RA21895D.

[37] D. Murphy, M.N. de Pinho, An ATR-FTIR study of water in cellulose acetate membranes prepared by phase inversion, J. Membr. Sci., 106 (1995) 245-257.

[38] M.R. Ganjali, R. Zare-Dorabei, P. Norouzi, Design and construction of a novel optical sensor for determination of trace amounts of dysprosium ion, Sens. Actuatrs B: Chem., 143 (2009) 233-238.

[39] R. Zare-Dorabei, R. Rahimi, A. Koohi, S. Zargari, Preparation and characterization of a novel tetrakis(4hydroxyphenyl)porphyrin-graphene oxide nanocomposite and application in an optical sensor and determination of mercury ions, RSC Adv. 5 (2015) 93310-93317.

[40] M.R. Pourjavid, M. Rezaee, M.H. Hosseini, T. Razavi, Monitoring of praseodymium (III) ions in aqueous solutions, soil and sediment samples by a PVC membrane sensor based on a furan-triazole derivative, Quím. Nova 35 (2012) 1973-1980. 


\section{Figure Captions:}

Fig. 1, Fabrication scheme of mesoprous Sba-15 paste.

Fig. 2, Structure of N, N'-bis(salicylidene)-1,3-ethylenediamine (BSEA) and possible schemes of reaction between SBA-15-BSEA with membrane.

Fig. 3, FT-IR spectra (a), low-angle XRD pattern (b), TEM image (c) and diagram of pore size distribution and $\mathrm{N}_{2}$ adsorption-desorption isotherms (d) of mesoporous SBA-15

Fig. 4, ATR-FT-IR spectra of triacetyl cellulose and triacetyl cellulose-SBA-15-BSEA (a), SEM image of triacetyl cellulose (b) and SEM image of triacetyl cellulose-SBA-15$\operatorname{BSEA}(\mathrm{c})$

Fig. 5, Comparison of absorbance spectra of optode film response by proposed method and current method (a) and absorbance spectra of optode film response to $\operatorname{Pr}(\mathrm{III})$ ions between 0.0 and $60 \mathrm{ng} \mathrm{mL}^{-1}$ at $\mathrm{pH} 5.0$ (b)

Fig. 6, pH effect on the optode film response

Fig. 7, Response time curve of the film optode at $420 \mathrm{~nm}$ when the film was exposed to $90 \mathrm{ng}$ $\mathrm{mL}^{-1} \operatorname{Pr}(\mathrm{III})$ ion.

Fig. 8, the optode film response versus the $\operatorname{Pr}(\mathrm{III})$ ion concentration in the range of 10-190 ng $\mathrm{mL}^{-1}$ at $\mathrm{pH} 5.0$ and $420 \mathrm{~nm}$.

Fig. 9, Absorbance variation of the membrane at $420 \mathrm{~nm}$ for repeatedly exposing in to $90 \mathrm{ppb}$ $\operatorname{Pr}(\mathrm{III})$ solution, $1.0 \mathrm{M}$ thiourea and $\mathrm{NaOH}$ solution. 


\section{Table Captions}

Table 1. Summary report of SBA-15 properties.

Table 2. Influence of the foreign ions on the $\operatorname{Pr}(\mathrm{III})$ determination of $90 \mathrm{ng} \mathrm{mL}^{-1}$

Table 3. Results of the recovery of $\operatorname{Pr}($ III) ion in three samples by spike method.

Table 4. Comparison of analytical parameters of proposed $\operatorname{Pr}(\mathrm{III})$ optical sensor with other methods for determination of praseodymium. 


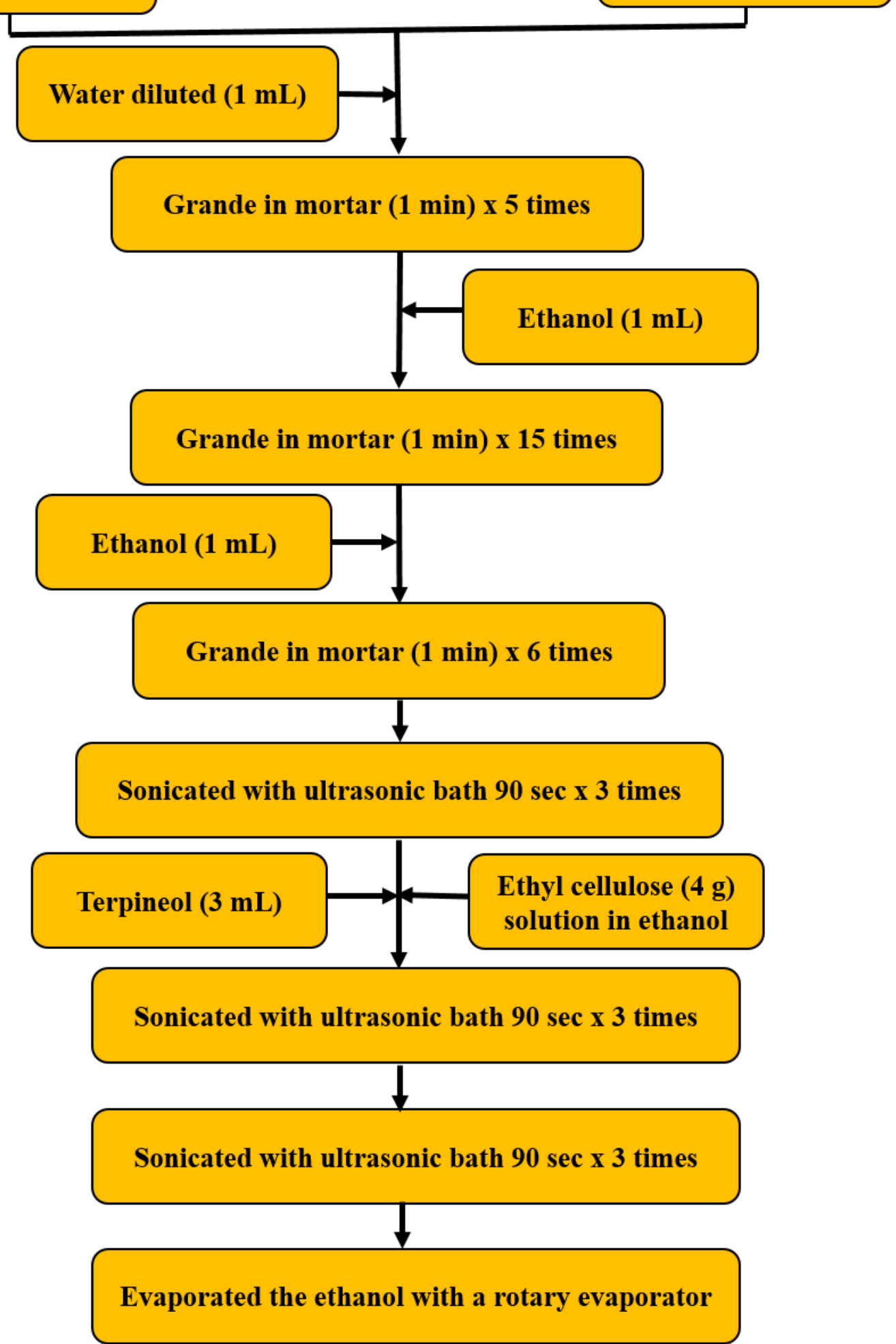


<smiles>NCCN=Cc1ccccc1O</smiles><smiles>Oc1ccc(/C=N/CC/N=C/c2ccccc2O)c(O)c1</smiles>

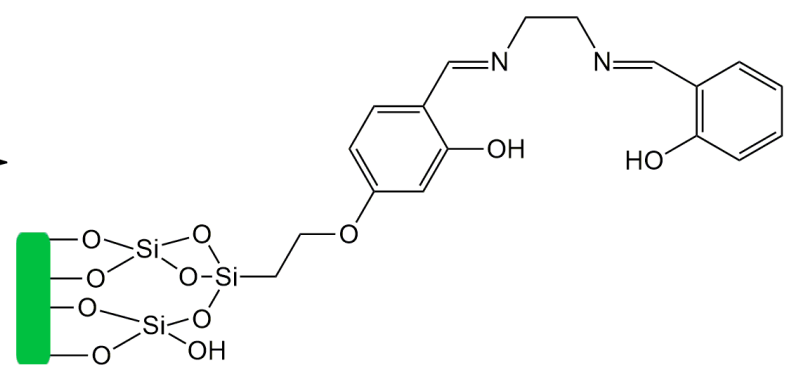

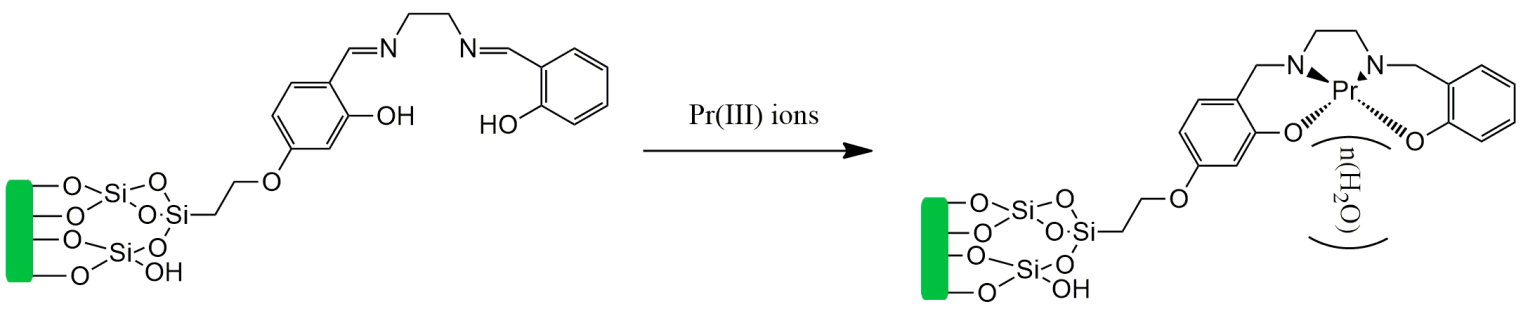



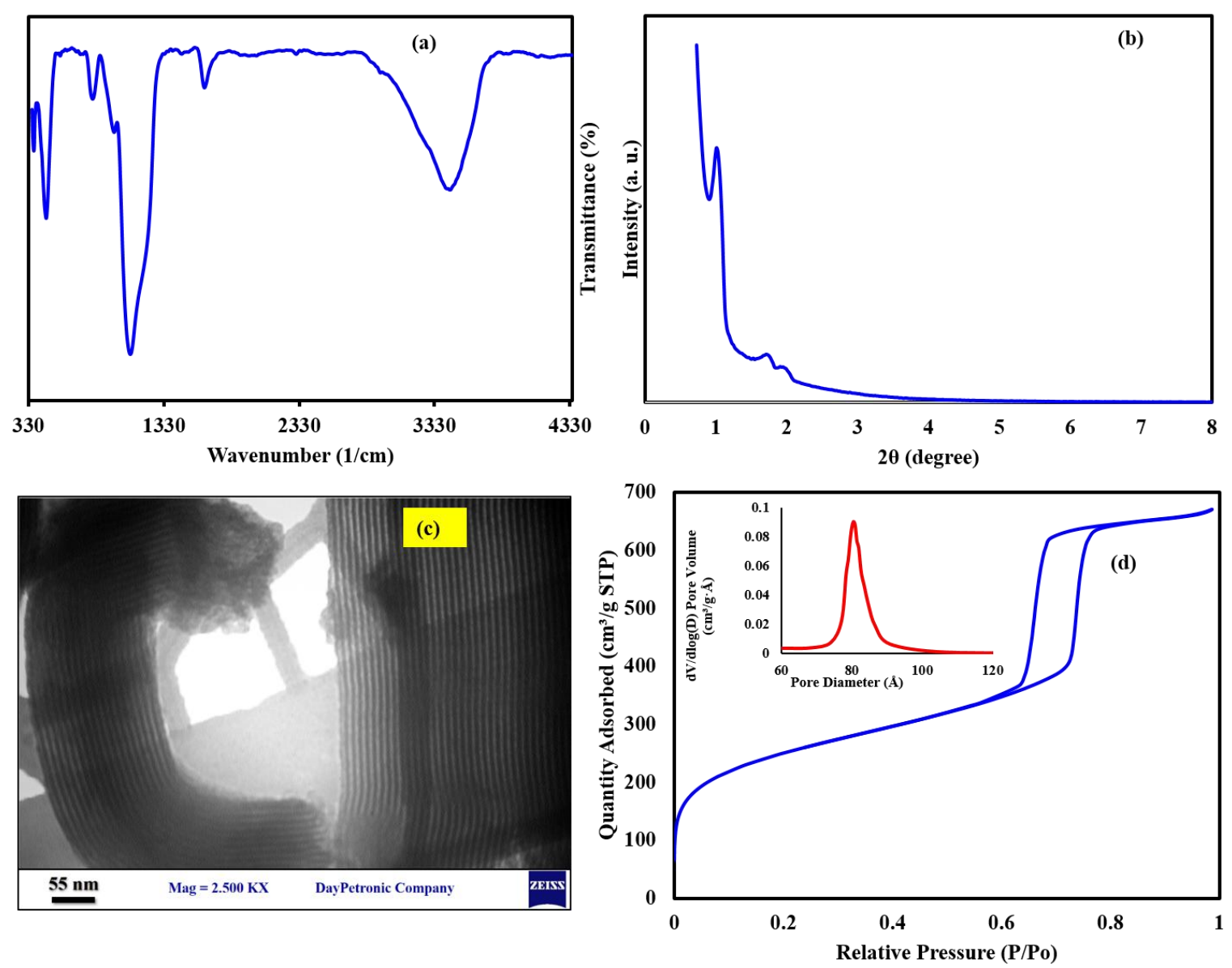

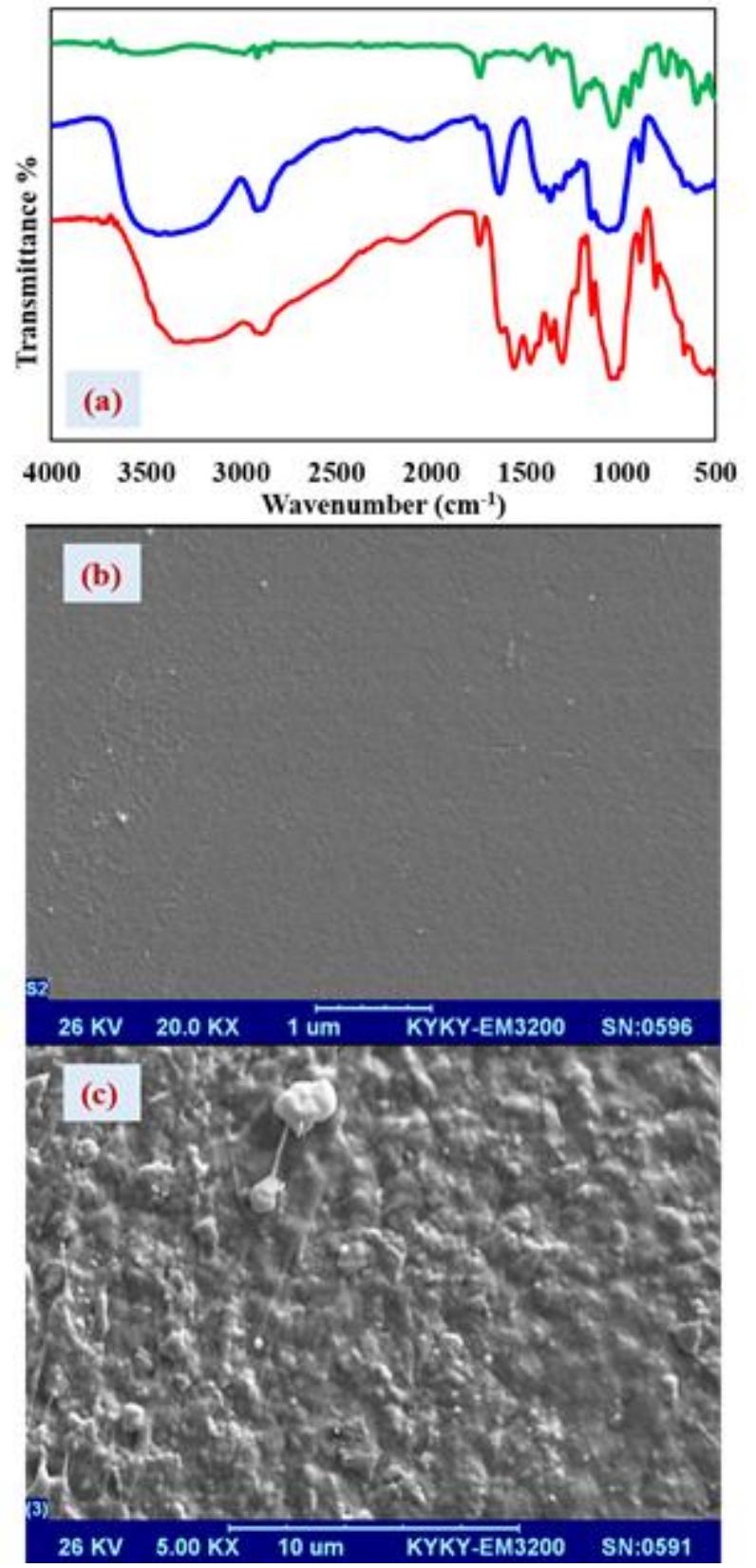

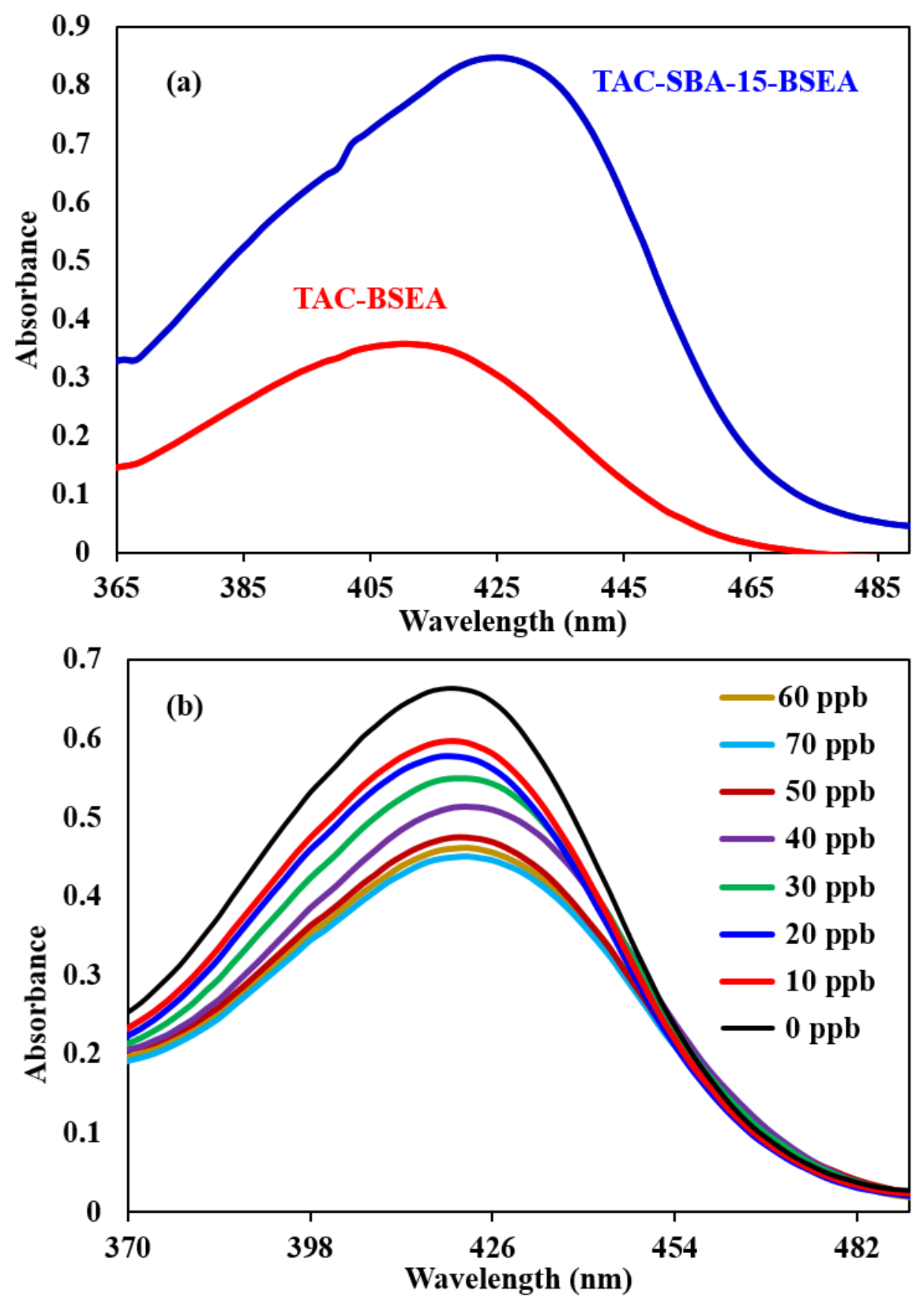


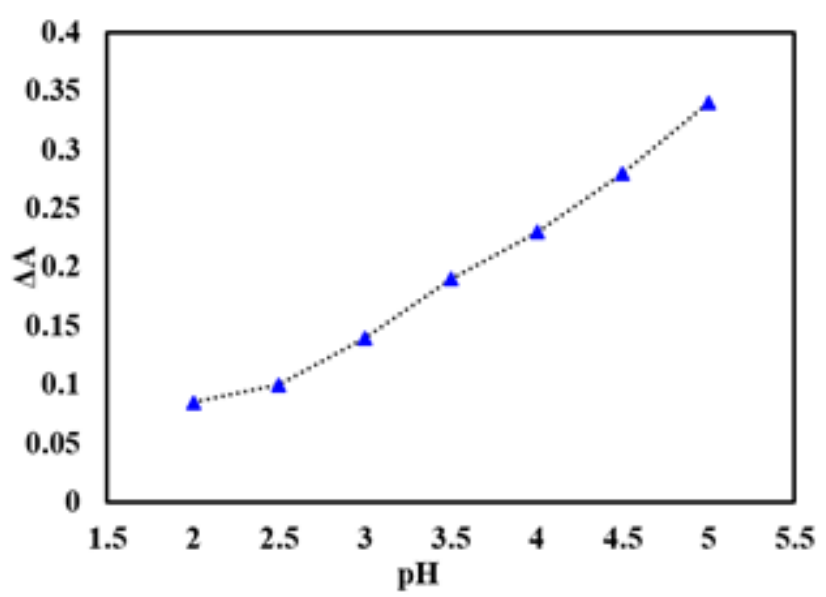




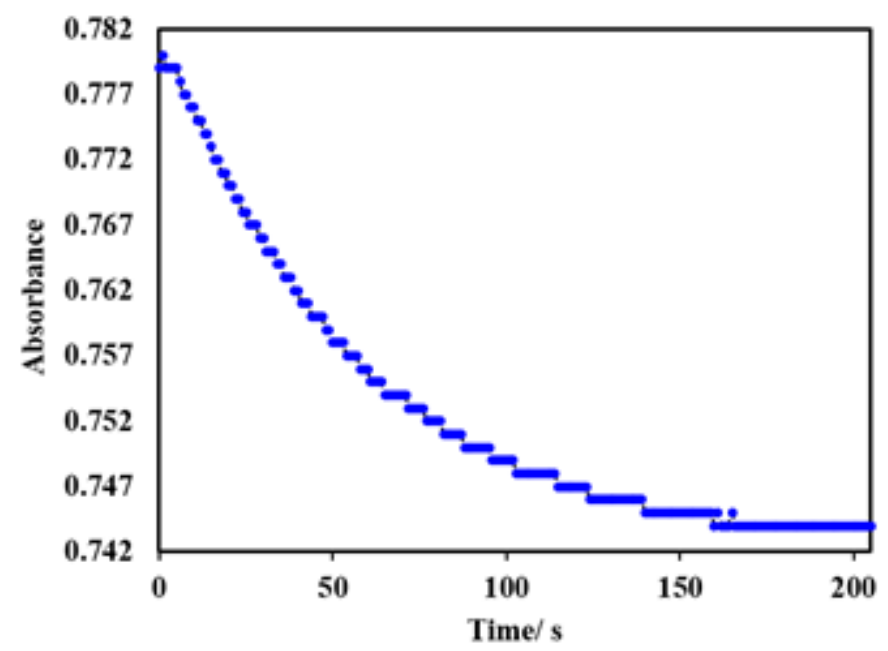




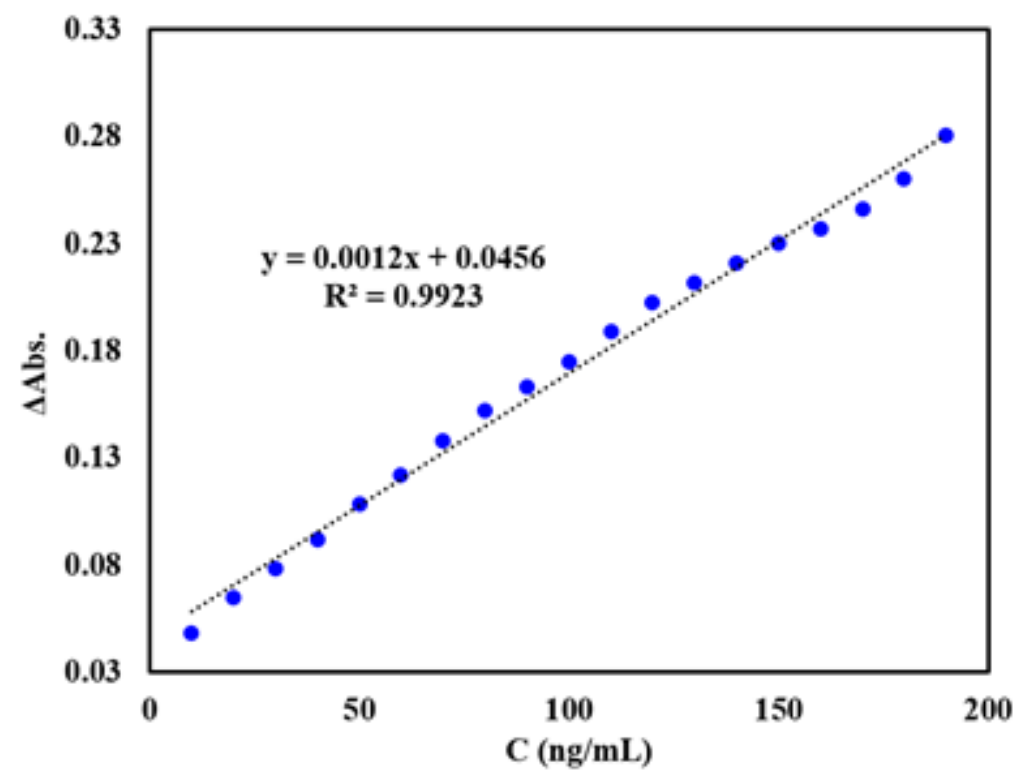




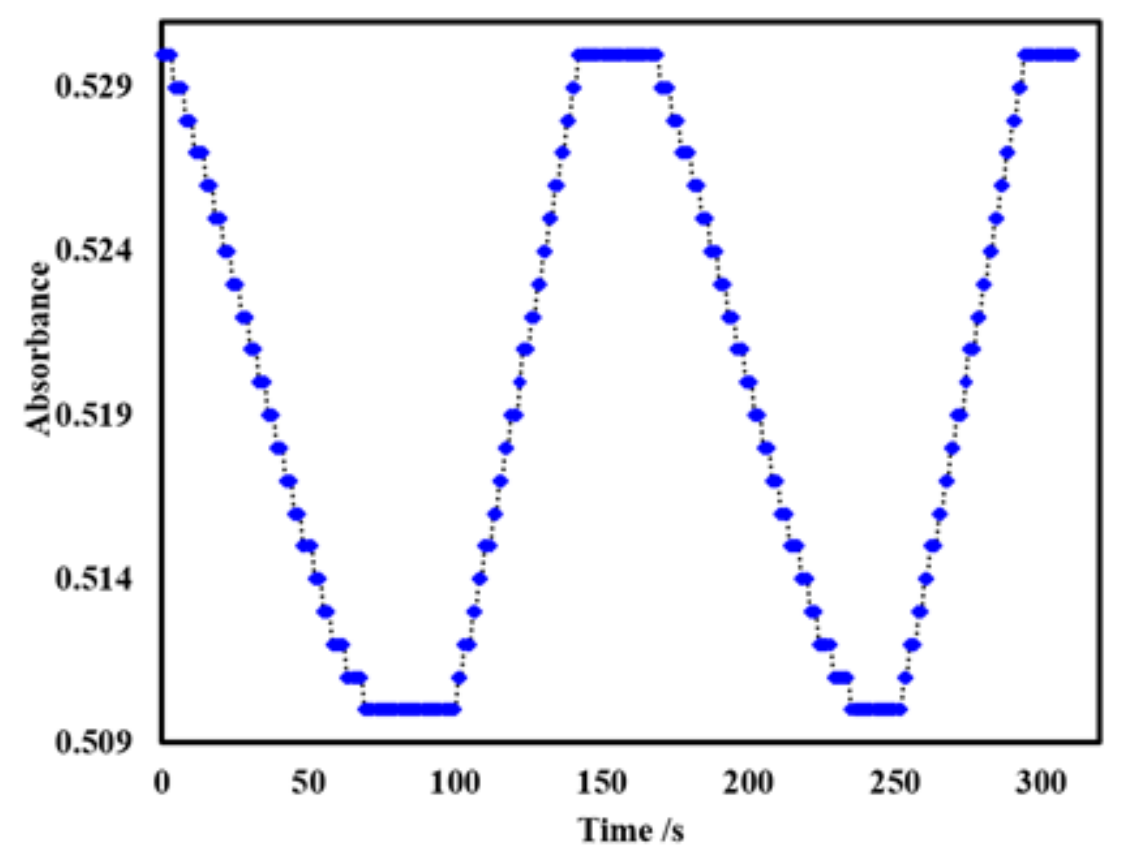




\section{Table 1.}

Summary report of SBA-15 properties.

\begin{tabular}{lc}
\hline \multicolumn{1}{c}{ Surface Area } & \\
BET Surface Area: & $869.3 \mathrm{~m}^{2} \mathrm{~g}^{-1}$ \\
Langmuir Surface Area & $1079.9 \mathrm{~m}^{2} \mathrm{~g}^{-1}$ \\
BJH Adsorption cumulative surface area of pores & \\
between $17.000 \AA$ and $3000.000 \AA$ width: & $662.5 \mathrm{~m}^{2} \mathrm{~g}^{-1}$ \\
\hline$\quad$ Pore Volume & $1.034 \mathrm{~cm}^{3} \mathrm{~g}^{-1}$ \\
BJH Adsorption cumulative volume of pores & \\
$\begin{array}{l}\text { between } 17.000 \AA \text { and } 3000.000 ~ \AA \text { width: } \\
\text { t-Plot micropore volume }\end{array}$ & $0.096 \mathrm{~cm}^{3} \mathrm{~g}^{-1}$ \\
\hline$\quad$ Pore Size & $85 \AA$ \\
\hline
\end{tabular}


Table 2.

Influence of the foreign ions on the Pr (III) determination of $90 \mathrm{ng} \mathrm{mL}^{-1}$.

\begin{tabular}{lc}
\hline \multicolumn{1}{c}{ Interferent } & Tolerance limit \\
\hline $\mathrm{Ce}^{3+}, \mathrm{La}^{3+}, \mathrm{Nb}^{3+}, \mathrm{Er}^{3+}$ & 150 \\
$\mathrm{Zn}^{2+}, \mathrm{Hg}^{2+,} \mathrm{Ni}^{2+,} \mathrm{Fe}^{2+}, \mathrm{Pb}^{2+}$ & 300 \\
$\mathrm{Cr}^{3+}, \mathrm{Cd}^{2+}, \mathrm{Cu}^{2+}$ & 700 \\
$\mathrm{~K}^{+}, \mathrm{Ba}^{2+}, \mathrm{Ca}^{2+}$ & 1000 \\
$\mathrm{SO}_{4}{ }^{2-}, \mathrm{NO}_{3}{ }^{-}, \mathrm{CO}_{3}{ }^{2-}, \mathrm{Cl}^{-}$ & 1600 \\
\hline
\end{tabular}

${ }^{\text {a }}$ Maximum ratio of the foreign ions to the lanthanum ions $90 \mathrm{ng} \mathrm{mL}^{-1}$ giving an error of $<5 \%$. 
Table 3.

Results of the recovery of $\operatorname{Pr}(\mathrm{III})$ ion in three samples by spike method.

\begin{tabular}{lcccc}
\hline Sample & $\begin{array}{r}\text { Pr(III) added } \\
\left(\mathrm{ng} \mathrm{ml}^{-1}\right)\end{array}$ & $\begin{array}{c}\text { Pr(III) found } \\
\left(\mathrm{ng} \mathrm{ml}^{-1}\right)\end{array}$ & $\begin{array}{c}\text { R.S.D. \% } \\
(\mathrm{n}=3)\end{array}$ & Recovery (\%) \\
\hline Mineral water & 0 & $\mathrm{ND}^{\mathrm{a}}$ & - & - \\
& 90 & 88.1 & 0.95 & 97.88 \\
Tap water & 0 & $\mathrm{ND}$ & - & - \\
& 90 & 90 & 1.00 & 100 \\
Well water & 0 & $\mathrm{ND}$ & - & - \\
& 90 & 94.4 & 1.21 & 104.77 \\
\hline
\end{tabular}

\footnotetext{
${ }^{\mathrm{a}}$ Not detected.
} 


\section{Table 4.}

Comparison of analytical parameters of proposed $\operatorname{Pr}$ (III) optical sensor with other methods for determination of praseodymium.

\begin{tabular}{lccccll}
\hline Ionophore & $\begin{array}{c}\mathrm{DL}^{\mathrm{a}} \\
\left(\mathrm{ng} \mathrm{mL}^{-1}\right)\end{array}$ & $\begin{array}{c}\mathrm{RL}^{\mathrm{b}} \\
\left(\mathrm{ng} \mathrm{mL}^{-1}\right)\end{array}$ & RSD & Sample & $\begin{array}{l}\text { Measured } \\
\text { signal }\end{array}$ & Ref. \\
\hline NAFT & 3.0 & $5.9-29500$ & 1.1 & Tap, minral and river water & Potential & {$[40]$} \\
\hline BMT & 38 & $59-590$ & - & Soils and Sediments & Potential & {$[3]$} \\
\hline LMFX & 850 & $3500-65000$ & 1.8 & Buffer solution & Absorbance & {$[8]$} \\
\hline L & 5.0 & $8.0-142$ & - & Tap and river water samples & Fluorescence & {$[2]$} \\
\hline BSEA & 5.0 & 10 to 90 & 1.6 & Tap, minral and river water & Absorbance & This work \\
\hline
\end{tabular}

\footnotetext{
${ }^{a}$ Detection limit.

${ }^{\mathrm{b}}$ Linear range.
} 

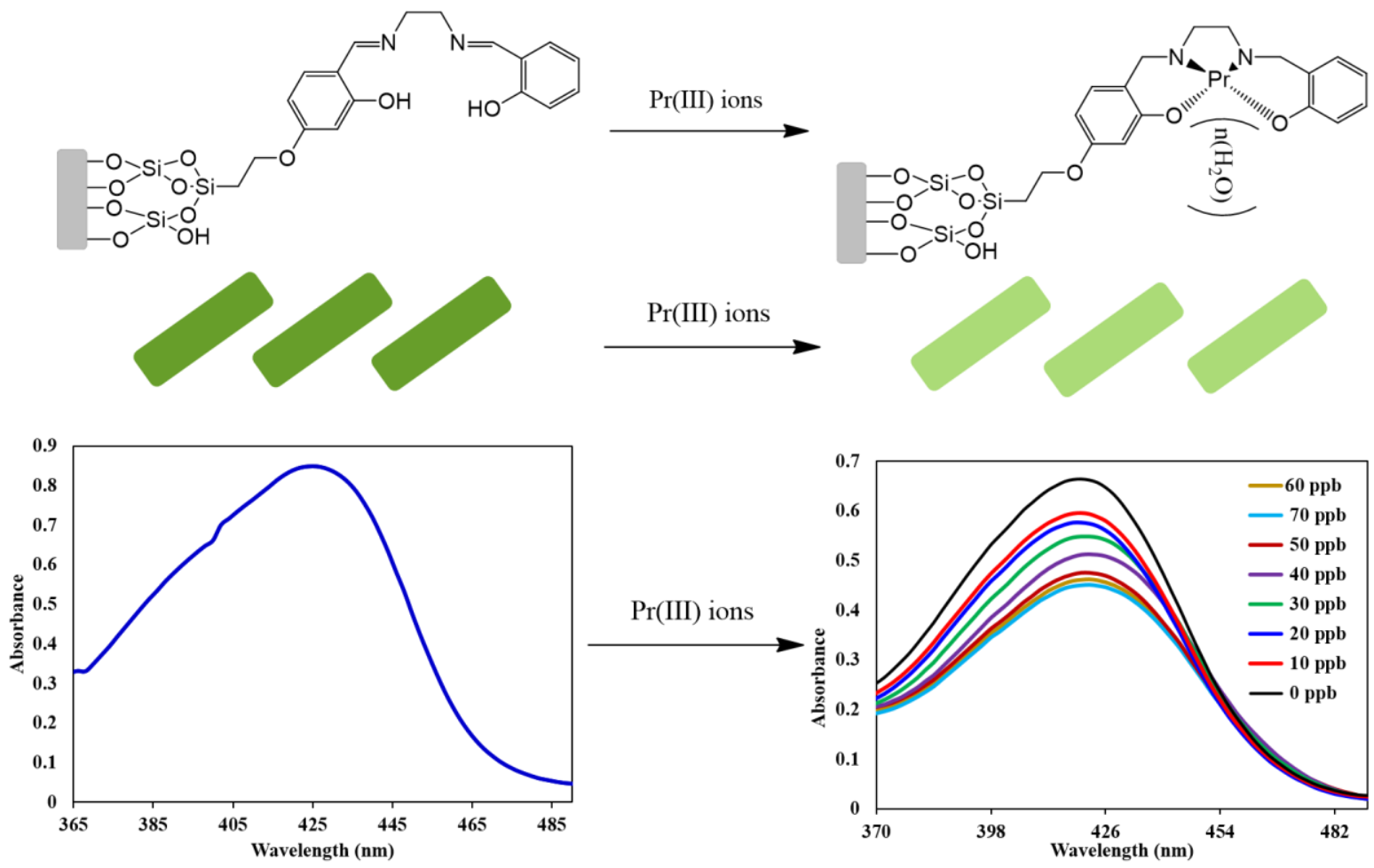